\title{
Effect of melatonin and removal of pouch young on the seasonality of births in the marsupial possum, Trichosurus vulpecula
}

\author{
R. T. Gemmell \\ Department of Anatomy, University of Queensland, St Lucia, Brisbane, Queensland 4067, Australia
}

\begin{abstract}
Summary. Melatonin implants were placed in 5 adult female possums during December. Births were observed from 31 March to 12 April in 4 control possums, and on 16 January, 1 and 6 February, 27 March and 27 April in the melatonin-treated animals. Melatonin would appear to have advanced the start of the breeding season in 3 of the 5 animals. Following removal of pouch young a subsequent birth is more likely to occur when young are removed early in the breeding season. These results would suggest that daylength may play a role in the initiation of the breeding season and the stimulus to mate diminishes from March through to September. Nevertheless, if the environmental conditions are favourable a secondary peak of births can occur in the later part of the year.
\end{abstract}

\section{Introduction}

The brushtail possum, Trichosurus vulpecula, exhibits an annual seasonality in breeding activity (Tyndale-Biscoe, 1955; Lyne \& Verhagen, 1957; Pilton \& Sharman, 1962; Dunnet, 1964; Gemmell et al., 1986, 1987). Although the majority of births occur during the months April and May in most regions of Australasia, the start and finish of the breeding season vary with locality. The start of the breeding season for the possum appears to vary from January in Adelaide (Pilton \& Sharman, 1962) through to April in Tasmania (Lyne \& Verhagen, 1957). Births have been observed in all months of the year although the incidence of births in the months October through to and including February is low. In the Australian Capital Territory and New South Wales a second peak of breeding was observed during September and October (Lyne \& Verhagen, 1957; Dunnet, 1964), although this smaller peak has not been observed in the New Zealand, Tasmanian, South Australian and Queensland studies (Tyndale-Biscoe, 1955; Lyne \& Verhagen, 1957; Pilton \& Sharman, 1962; Gemmell et al., 1986). In Queensland, births were first observed during March and continued throughout the year until November; no births have been recorded during December, January and February (Gemmell et al., 1987).

The environmental cues employed by the possum in regulating the onset and duration of the breeding season are not known. The occurrence of 7 births all within 19 days in a captive colony of possums (Gemmell et al., 1986) would suggest that a parameter such as daylength may be involved. Plasma testosterone concentrations in the male possum fluctuated throughout the year and a seasonal cycle was observed, with a peak in testosterone concentration in March and a nadir in September. This annual plasma testosterone profile correlated well with the rate of change of daylength (Gemmell et al., 1987). However, the start of breeding varies greatly with location and it is unlikely that daylength is the only parameter governing the start and duration of the breeding season.

The pineal gland and the hormone melatonin are thought to be influenced by changing daylength and have been implicated in seasonal reproduction in many eutherian mammals (Reiter, 
1980; Kennaway, 1984). The effect of melatonin on reproductive activity has been examined in 3 species of marsupial, the tammar wallaby (Macropus eugenii) (McConnell \& Tyndale-Biscoe, 1985), Bennett's wallaby (Macropus rufogriseus) (Loudon et al., 1985) and the bandicoot (Isoodon macrourus) (Gemmell, 1987). The two wallabies exhibit embryonic diapause (Tyndale-Biscoe, 1984) and amongst the marsupials they can be considered to be highly specialized in their reproductive strategy (Gemmell et al., 1987). The bandicoot and the brushtail possum, which are longday and short-day breeders respectively, do not exhibit embryonic diapause. In this study, the effect of an implant of melatonin on the initiation of breeding activity was examined in the brushtail possum. Melatonin implants were also placed in the males to remove any possible seasonal effect on the male reproductive processes.

If pouch young are removed from the possum during the breeding season, ovulation occurs about 8-9 days later, and if mating is successful birth occurs $\sim 26$ days after removal of the young (Pilton \& Sharman, 1962; Curlewis \& Stone, 1986; Gemmell et al., 1987). Following removal of the pouch young in the early months of the year, January through to June, all possums returned to oestrus, but in the later part of the year oestrus failed to occur in an increasing number of females (Pilton \& Sharman, 1962). Curlewis \& Stone (1986) reported that the age of the removed young had an effect on the time taken for oestrus and mating to occur. Mating was more likely when the pouch young were removed at an early age; $68.8 \%$ of females mated at the first oestrus after removal of newborn young, whereas only $14.3 \%$ of females mated after the removal of young greater than 85 days of age (Curlewis \& Stone, 1986). In this study, the incidence of births following removal of young of different ages and at different months of the year was examined in the brushtail possum.

\section{Materials and Methods}

Animals. Ten adult female and 8 adult male possums, $T$. vulpecula, were used in this study, the breeding colony being established from possums trapped in the environs of Brisbane. Two males together with 2 or 3 female possums were housed in each of 4 fully enclosed yards, measuring $20 \mathrm{~m}^{2}$. The female possums were examined weekly and the size and morphology of the teats noted, as these enlarge close to parturition. The date of birth of pouch young was determined either by observing the day of birth or by estimating the age of pouch young from the length of the head and the total body weight according to the method described by Lyne \& Verhagen (1957).

Melatonin implants. On 4 and 11 December, 1985, Possums 6 and 7 and Possums 8,9 and 10 respectively received a subcutaneous implant of melatonin on the back between the shoulders. These implants consisted of a sealed envelope of Silastic sheeting, surface area $25 \mathrm{~cm}^{2}$ (500-1 sheeting, Dow Corning, Midland, MI, U.S.A.) containing 0.2 g melatonin (Sigma, Poole, Dorset, U.K.) (Lincoln et al., 1984). One male possum in each of the 4 yards also received a similar implant. Five control possums which did not receive implants were housed in the same enclosures as the possums with melatonin implants. Blood samples were obtained weekly from all 10 female possums until a young was first observed in the pouch, with the exception of Possum 5 which did not give birth. Blood sampling for this possum ceased on 30 May.

Progesterone assay. Plasma progesterone concentrations were determined by radioimmunoassay employing the method described previously for the bandicoot (Gemmell, 1979; Gemmell et al., 1987), using sheep anti-progesterone-11-hemisuccinate-bovine serum albumin (antiserum No. 334) kindly donated by Dr R. I. Cox, CSIRO, Prospect, New South Wales, Australia. The antiserum is highly specific for progesterone, the only significant cross-reaction being with $11 \beta$-hydroxyprogesterone $(11.9 \%)$. The limit of the sensitivity of the assay was $25 \mathrm{pg} /$ tube and the intra- and inter-assay coefficients of variation were $12 \cdot 5 \%(n=5)$ and $14.0 \%(n=10)$ respectively. The assay buffer blank was less than $0.1 \mathrm{ng} / \mathrm{ml}$ and the efficiency of extraction was $87.0 \%(n=10)$.

Removal of pouch young and subsequent births. From 1983 to 1985,47 pouch young were removed from their respective mothers during the months March through to November. The age of the young and the date of removal were noted. The females were housed with mature males and were examined $20-30$ days after removal of the pouch young for the presence of newborn young.

\section{Results}

Four of the 5 control possums gave birth on 31 March (Nos 1 and 2), 8 April (No. 3), 12 April (No. 4) and 1 possum (No. 5) failed to give birth. Three possums (Nos 1, 2 and 4) became pregnant 


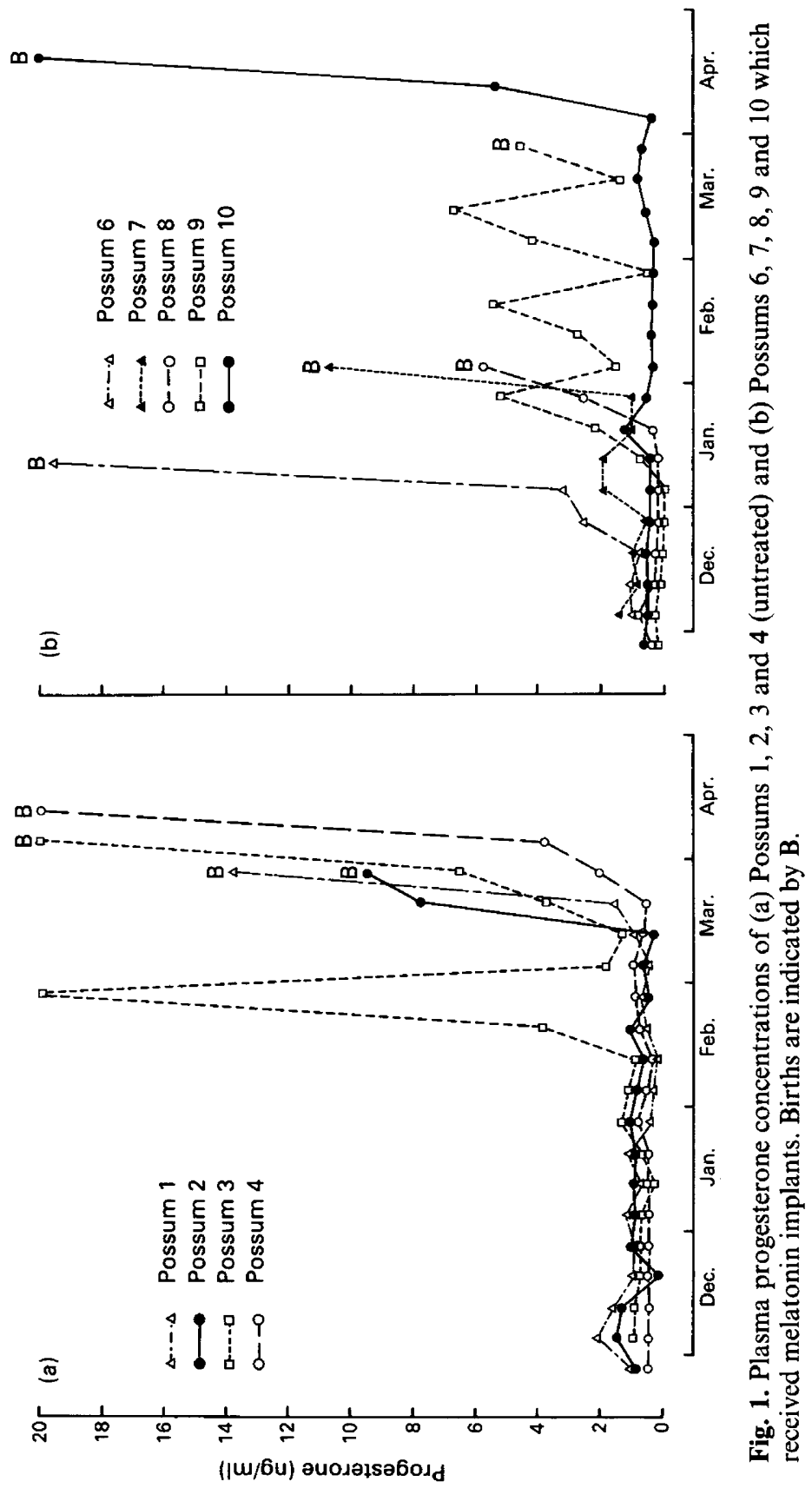


following their first ovulation of the season as indicated by the plasma progesterone concentrations and teat morphology. The weekly plasma progesterone concentrations for Possum 3 indicated that an oestrous cycle had occurred before the subsequent birth. The increase in plasma progesterone observed in late February was accompanied by an increase in teat size. The plasma progesterone concentrations are presented for Possums 1, 2, 3 and 4 (Fig. 1a). Progesterone concentrations remained at basal levels for Possum 5.

The 5 possums (Nos 6-10) which received melatonin implants gave birth on 16 January, 1 and 6 February, 27 March and 27 April respectively. The young of Possums 6, 7 and 8 were removed on 4 March, 6 February and 4 March, and births subsequently occurred 26, 25 and 24 days later on 30, 3, and 28 March respectively. Possums 6, 7, 8 and 10 gave birth at the first ovulation of the season as indicated by plasma progesterone concentrations, but there was evidence of 3 non-pregnant cycles in Possum 9 before the first birth of the breeding season and an increase in the teat size and an enlargement of the pouch was noted on 28 January. The plasma progesterone concentrations are presented for Possums 6, 7, 8, 9 and 10 (Fig. 1b).

Three possums (Nos 1, 4 and 6) had been housed within the colony for 3, 2 and 2 years respectively. The first births of the breeding season for Possum 1 occurred on 22 March 1984, 2 April 1985 and 31 March 1986 and Possum 4 gave birth on 9 April 1985 and 12 April 1986. The first birth of the season for Possum 6 was on 26 March during 1985, but after receiving a melatonin implant the first birth of 1986 occurred on 16 January.

Table 1. Effect of age of pouch young removed from possums on the subsequent birth

\begin{tabular}{ccc}
\hline $\begin{array}{c}\text { Age of pouch young } \\
\text { (days) }\end{array}$ & $\begin{array}{c}\text { No. of removals } \\
\text { of young }\end{array}$ & Births \\
\hline 1 & 2 & 2 \\
I-7 & 5 & 0 \\
$8-28$ & 30 & 17 \\
$29-84$ & 9 & 1 \\
85 & 1 & 0 \\
\hline
\end{tabular}

Table 1 shows the births following the removal of pouch young, with the animals grouped according to age. These results do not support the hypothesis that the probability of a subsequent birth decreases with the increasing age of the young removed. When the data (Table 1) were fitted to a linear logistic model it was found that there was no evidence of a decline in the number of births following removal of pouch young of increasing age $\left(\chi_{1}^{2}=2 \cdot 42, P>0 \cdot 1\right)$. If the number of births following removal of pouch young are examined with respect to the month of the year, it appears that the period of the year influences the probability of birth (Table 2). Testing the hypothesis that all months have the same proportion of births following the removal of pouch young, there is strong evidence that this hypothesis is incorrect $\left(\chi_{8}^{2}=28 \cdot 3, P<0.005\right)$. If the ages of the young removed during April (range 13-31 days, mean 18.4 \pm 2.0 (s.e.m.) days, $n=11$ ) are compared with those removed in October (range 2-90 days, mean $25 \cdot 5 \pm 8 \cdot 0$ (s.e.m.) days, $n=10$ ), then it is apparent that the month of the year rather than the weight of the young removed influences the probability of a subsequent birth.

Eight possums which had young removed in April $(\mathrm{N}=3)$, May $(\mathrm{N}=4)$ and June $(\mathrm{N}=1)$ did not give birth immediately after removal. Three of these animals were not re-examined. Of the remaining 5 animals 1 possum gave birth in July (removal of young in April) and 2 possums gave birth in October (removal of young in May). The remaining 2 did not give birth until the next season. 
Table 2. Effect of month of year on the number of births in possums following removal of pouch young

\begin{tabular}{lcc}
\hline Months & $\begin{array}{c}\text { No. of removals } \\
\text { of young }\end{array}$ & Births \\
\hline March & 2 & 2 \\
April & 11 & 8 \\
May & 9 & 5 \\
June & 4 & 3 \\
July & 5 & 1 \\
August & 3 & 1 \\
September & 1 & 0 \\
October & 10 & 0 \\
November & 2 & 0 \\
\hline
\end{tabular}

\section{Discussion}

An exogenous implant of melatonin administered to the possum, $T$. vulpecula, in the anoestrous period stimulates the follicles to develop and ovulation to occur. Births were observed in January and February following melatonin treatment. Births have not previously occurred during these months in our breeding colony or in the wild population located in the environs of Brisbane (Gemmell, et al., 1987).

The effect of exogenous melatonin on reproductive activity has been examined in many species of mammals. Seasonally breeding mammals can be divided into three groups: continuous, shortday and long-day breeders. With short-day breeders such as the red deer, Cervus elaphus, feeding melatonin to hinds caused the onset of oestrus to occur in late August and early September, 2-8 weeks in advance of control hinds (Adam \& Atkinson, 1984). Similar results were observed by Webster \& Barrell (1985) in New Zealand. Calves were born earlier in the hinds exposed to shortened photoperiod or melatonin treatment than in control hinds. Continuous exposure to melatonin in early summer will induce premature seasonal testicular development in male red deer, an effect dependent on the secretion of luteinizing hormone-releasing hormone and similar to that produced by exposure to short daylengths (Lincoln et al., 1984). As with deer, melatonin implants in rams during exposure to long days resulted in a rapid 'switch on' of reproductive redevelopment similar to that produced by exposure to short days (Lincoln \& Ebling, 1985).

The overall results are consistent with the view that melatonin is the physiological hormone that relays the effects of changing photoperiod on reproduction and other seasonal features, and that continuous exogenous melatonin from an implant interferes with the normal 'signal' and produces an over-riding short-day response (Lincoln \& Ebling, 1985).

Melatonin has the opposite effect on reproductive activity when administered to long-day breeders. Both short photoperiod and melatonin have a repressive effect on the sexual development of young male white-footed mice (Petterborg \& Reiter, 1980). Similarly, melatonin administered to rabbits mimicked the transfer from long-day to short-day by increasing testis regression (Boyd, 1985). Similar hormonal treatment inhibited ovulation and pregnancy in the marsupial bandicoot, I. macrourus, a long-day breeder (Gemmell, 1987). Melatonin administered to another 2 marsupial species, the tammar wallaby, Macropus eugenii, and Bennett's wallaby, Macropus rufogriseus, rapidly caused termination of seasonal diapause (McConnell \& Tyndale-Biscoe, 1985; Loudon et al., 1985). The possum, T. vulpecula, is a short-day breeder and does not exhibit embryonic diapause (Tyndale-Biscoe, 1984).

The procedure of removing pouch young from the possum during the breeding season causes the possum to ovulate and mate in about 9 days and birth occurs 25-26 days after removal of the 
pouch young (Pilton \& Sharman, 1962; Curlewis \& Stone, 1986; Gemmell et al., 1987). Pilton \& Sharman (1962) observed that the probability of the possum giving birth after removal of the pouch young decreased with the progression of the breeding season. All the females from which the young were removed in the months of January to May inclusive came into oestrus 6-13 days after the removal of the young. The population of females which returned to oestrus declined following removal of young in later months (Pilton \& Sharman, 1962). Similar results were obtained in this study with a larger proportion of females giving birth after removal of pouch young in the months March to June inclusive. However, very few births occurred in the later part of the year. Curlewis \& Stone (1986) have suggested that the age of the pouch young may influence the probability of return to oestrus; the older the pouch young the less chance of a return to oestrus. The results obtained in this study do not support this hypothesis (see Table 1). Despite the apparent decline in the return to oestrus following removal of pouch young of increasing age in the Curlewis \& Stone (1986) data and the lack of a similar decline in the present data there would appear to be no difference in the two sets of information. Performing a complete logistic model analysis to the proportion of births following the removal of pouch young it was found that the two sets of data were not inconsistent $\left(\chi_{1}^{2}=0 \cdot 02\right.$, not significant $)$. It is probable that since the main breeding period is March to May in Sydney, most of the large pouch young in the Curlewis \& Stone (1986) study were removed in the later part of the year and so the probability of a return to oestrus was more likely to have been influenced by season than by the weight of young removed.

In studies in New Zealand (Gilmore, 1969), the Australian Capital Territory (Dunnet, 1964) and in New South Wales (Lyne \& Verhagen, 1957), a second smaller peak of breeding activity was observed in the months September, October and November. With 3 possums of this study, pregnancy and births did not follow the removal of the pouch young in April and May, but births occurred in July and October. The existence of two peaks of breeding activity in certain studies could be explained by the following hypothesis. The possum is stimulated to breed during March and breeding activity continues throughout the year until November, declining slowly in the later part of the year. This would describe the pattern obtained in South Australia (Pilton \& Sharman, 1962), in New Zealand (Tyndale-Biscoe, 1955), in Tasmania (Lyne \& Verhagen, 1957) and in Queensland (Gemmell et al., 1987). If climatic factors, such as temperature, can affect the stimulus for the possum to breed, the two peaks of breeding observed by Lyne \& Verhagen (1957), Dunnet (1964) and Gilmore (1969) may be due to a suppression of activity during the colder months of the winter of the southern hemisphere. Therefore, climatic features may also influence breeding activity.

This study would suggest that the rate of change of daylength probably plays an important role in determining the start of the breeding season of the possum. However, as stated previously (Gemmell et al., 1986), the variation in the start of the breeding season, depending on location, would suggest that factors other than photoperiod may influence reproductive activity in the brushtail possum.

I thank the Australian Research Grants Scheme for financial assistance and A. Barnes, statistical adviser, Science Faculty, for his assistance with the statistical analysis.

\section{References}

Adam, C.L. \& Atkinson, T. (1984) Effect of feeding melatonin to red deer (Cervus elaphus) on the onset of the breeding season. J. Reprod. Fert. 72, 463-466.

Boyd, I.L. (1985) Effect of photoperiod and melatonin on testis development and regression in wild European rabbits (Oryctolagus cuniculus). Biol. Reprod. 33, 21-29.
Curlewis, J.D. \& Stone, G.M. (1986) Reproduction in captive female brushtailed possum Trichosurus vulpecula. Aust. J. Zool. 34, 47-52.

Dunnet, G.M. (1964) A field study of local populations of the brushtailed possum Trichosurus vulpecula. Aust. J. Zool. 34, 47-52.

Gemmell, R.T. (1979) The fine structure of the luteal cells 
in relation to the concentration of progesterone in the plasma of the lactating bandicoot Isoodon macrourus (Marsupialia: Peramelidae). Aust. J. Zool. 27, 501-510.

Germell, R.T. (1987) Influence of melatonin on the initiation of breeding season of the marsupial bandicoot, Isoodon macrourus. J. Reprod. Fert. 79, $261-265$.

GemmeH, R.T., Cepon, G. \& Barnes, A. (1986) Weekly variations in weight and plasma testosterone concentrations in the captive male possum, Trichosurus vulpecula. Gen. comp. Endocrin. 62, 1-8.

Gemmell, R.T., Hughes, R.L. \& Jenkin, G. (1987) Comparative studies on the hormonal profiles of progesterone and prostaglandin $F$ metabolite in the possum, Trichosurus vulpecula. In Possums and Opossums, Studies in evolution, Ed. M. Archer, Royal Zoological Society of New South Wales, and Surrey Beatty \& Sons, Sydney, (in press).

Gilmore, D.P. (1969) Seasonal reproductive periodicity in the male brush-tailed possum (Trichosurus vulpecula). J. Zool., Lond. 157, 75-98.

Kennaway, D.J. (1984) Pineal function in ungulates. Pineal Res. Rev. 2, 113-140.

Lincoln, G.A. \& Ebling, F.J.P. (1985) Effect of constant release implants of melatonin on seasonal cycles in reproduction, prolactin secretion and moulting in rams. J. Reprod. Fert. 73, 241-253.

Lincoln, G.A., Fraser, H.M. \& Fletcher, T.J. (1984) Induction of early rutting in male red deer (Cervus elaphus) by melatonin and its dependence on LHRH. J. Reprod. Fert. 72, 339-343.

Loudon, A.S.I., Curlewis, J.D. \& English, J. (1985) The effect of melatonin on the seasonal embryonic diapause of the Bennett's wallaby (Macropus rufogriseus rufogriseus). J. Zool., Lond. 206, 35-39.
Lywe, A.G. \& Verhagen, A.M.W. (1957) Growth of the marsupial Trichosurus vulpecula and a comparison with some higher mammals. Growth 21, 167-195.

McCemeh, S.J. \& Tyndele-Biscee, C.H. (1985) Response in peripheral plasma melatonin to photoperiod change and the effects of exogenous melatonin on seasonal quiescence in the tammar, Macropus eugenii. J. Reprod. Fert. 73, 529-538.

Petterborg, L.J. \& Reiter, R.J. (1980) Effect of photoperiod and melatonin on testicular development in the white-footed mouse, Peromyscus leucopus. J. Reprod. Fert. 60, $209-212$.

Pilton, P.E. \& Sharman, G.B. (1962) Reproduction in the marsupial Trichosurus vulpecula. J. Endocr. 25, 119-136.

Reiter, R.J. (1980) The pineal and its hormones in the control of reproduction and mammals. Endocr. Rev. 1, 109-131.

Tyndale-Biscoe, C.H. (1955) Observations on the reproduction and ecology of the brush-tailed possum Trichosurus vulpecula Kerr (Marsupialia) in New Zealand. Aust. J. Zool. 3, 162-184.

Tyndale-Biscoe, C.H. (1984) Mammalia-Marsupialia. In Marshall's Physiology of Reproduction, 4th edn, vol. I, pp. 386-454. Ed. G. E. Lamming. Churchill Livingstone, Edinburgh.

Webster, J.R. \& Barrell, G.K. (1985) Advancement of reproductive activity, seasonal reduction in prolactin secretion and seasonal pelage changes in pubertal red deer hinds (Cervus elaphus) subjected to artificially shortened daily photoperiod or daily melatonin treatments. J. Reprod. Fert. 73, 255-260.

Received 9 October 1986 